Discussion Paper No. 08-082

\title{
International Scientist Mobility and the Locus of Technology Transfer
}

Jakob Edler, Heide Fier, and Christoph Grimpe

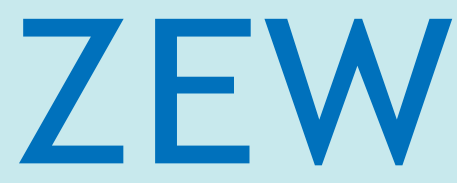

Zentrum für Europäische Wirtschaftsforschung $\mathrm{GmbH}$

Centre for European

Economic Research 


\title{
Discussion Paper No. 08-082 \\ International Scientist Mobility and the Locus of Technology Transfer
}

\author{
Jakob Edler, Heide Fier, and Christoph Grimpe
}

Download this ZEW Discussion Paper from our ftp server:

ftp://ftp.zew.de/pub/zew-docs/dp/dp08082.pdf

Die Discussion Papers dienen einer möglichst schnellen Verbreitung von neueren Forschungsarbeiten des ZEW. Die Beiträge liegen in alleiniger Verantwortung der Autoren und stellen nicht notwendigerweise die Meinung des ZEW dar.

Discussion Papers are intended to make results of ZEW research promptly available to other economists in order to encourage discussion and suggestions for revisions. The authors are solely responsible for the contents which do not necessarily represent the opinion of the ZEW. 


\section{Non-technical summary}

Scientific technology transfer has attracted considerable attention in the literature with a focus on the institutions (e.g. technology transfer offices), the agents involved in technology commercialisation or on the differentiation between formal and informal technology transfer mechanisms. Particularly the individual scientist has been shown to play a key role in technology transfer activities.

We focus on the question how the scale and locus of technology transfer is influenced by individual characteristics and the scientist's international mobility. The effects of brain drain, gain or circulation have been subject to an intensive debate, both in the literature and in policy making. It seems that mobility of scientists, although highly praised as important for knowledge transfer and build-up of networks, cooperation potential and the like, does not loose its negative connotation of some kind of loss for the sending 'system', institution or nation. There has, however, been little systematic research on how the mobility of university scientists influences their propensity to engage in technology transfer activities and, particularly, on how mobility influences the locus of such activities.

In a first step the mobility behaviour of university scientists is empirically explored by identifying subgroups with a characteristic mobility pattern. These subgroups are identified via latent class cluster analysis. Secondly, evidence is contributed on the determinants of technology transfer directed at the home or the (former) host countries of scientists. Regression analysis is used to approach this question. The empirical investigations are based on a sample of more than 500 German university scientists.

We find that scientists who transfer knowledge do so, generally speaking, both at home and abroad. In other words, there is a complementary relationship between both activities. Transferring knowledge abroad while being mobile thus will not diminish the activities and effects of subsequent transfers but rather increase them. Second, we can confirm that the intensity of mobility has a positive impact on the inclination to transfer knowledge in the host country: while the simple transfer of artefacts or licenses can be done with short contacts, interactive transfer activities need intensity. Third, our results tend to confirm that the more frequent scientists are internationally mobile, the more they engage in technology transfer to their home country. Hence, for a country, it apparently pays off if the scientists are frequently mobile to other countries. At the same time, those scientists who are only intensively mobile, i.e. who stay abroad for a longer period but less frequently, transfer less to Germany. 


\section{Das Wichtigste in Kürze}

Die Bedeutung des Technologietransfers aus wissenschaftlichen Einrichtungen für die Entwicklung und Wettbewerbsfähigkeit der nationalen Forschungslandschaft ist in den letzten Jahren zunehmend in den Fokus der wissenschaftlichen Literatur gerückt. Dabei haben sich die bisherigen Untersuchungen vor allem auf die Fragen konzentriert, welche Institutionen oder Wissenschaftler sich an Technologietransfer beteiligen und ob dieser Transfer über informelle bzw. formelle Transfermechanismen abläuft.

Im Rahmen dieser Studie wird untersucht, inwieweit individuelle Faktoren und die internationale Mobilität von Wissenschaftlern die Intensität und die Richtung von Technologietransfers beeinflussen. $\mathrm{Zu}$ dieser Problemstellung existiert bislang wenig empirische Literatur, obwohl gerade die Frage, ob internationale Mobilität von Wissenschaftlern zu einem Wissensabfluss oder Wissensgewinn für die jeweilige nationale Forschungslandschaft führt, Gegenstand lebhafter politischer und wissenschaftlicher Debatten ist. Dabei gilt die internationale Mobilität von Wissenschaftlern gemeinhin als notwendig und wichtig für den technologischen Austausch und den Aufbau von wissenschaftlichen Kooperationen und Netzwerken. Allerdings überwiegt bei vielen politischen und institutionellen Akteuren die Überzeugung, dass der durch internationale Mobilität verursachte, vermeintliche Wissensverlust größer ist, als der potenzielle Wissenszuwachs.

In einem ersten Schritt wird empirisch das Mobilitätsverhalten von mehr als 500 befragten deutschen Wissenschaftlern ausgewertet. Dabei werden mit Hilfe einer Clusteranalyse Untergruppen mit spezifischen Mobilitätsmustern bestimmt. In einem weiteren Schritt werden mithilfe einer Regressionsanalyse die Einflussfaktoren bestimmt, die dazu führen, dass sich die befragten deutschen Wissenschaftler an einem Technologietransfer nach Deutschland oder ins Ausland beteiligen.

Im Ergebnis zeigt sich, dass Wissenschaftler, die am Technologietransfer partizipieren, zumeist Wissen sowohl nach Deutschland als auch ins Ausland transferieren. Die Angst, dass internationale Mobilität zwangsläufig zu einem Nettoverlust von Wissen in dem Heimatland der Wissenschaftler führt, ist somit unbegründet. Allerdings zeigt sich im Rahmen unserer Studie, dass häufige, kürzere Auslandsaufenthalte eher zu einem Wissenstransfer nach Deutschland führen, während weniger häufige, aber dafür zeitlich intensivere Auslandsaufenthalte eher einen Wissenstransfer von Deutschland ins Ausland nach sich ziehen. 


\title{
International Scientist Mobility and the Locus of Technology Transfer
}

\author{
Jakob Edler ${ }^{\text {a }}$, Heide Fier ${ }^{\text {b }}$ and Christoph Grimpe ${ }^{\text {b, c, d, } 1}$ \\ ${ }^{a}$ Manchester Institute of Innovation Research, MBS, Manchester University (UK) \\ ${ }^{\mathrm{b}}$ ZEW - Centre for European Economic Research, Mannheim (Germany) \\ ${ }^{\mathrm{c}}$ Catholic University of Leuven (Belgium) \\ ${ }^{\mathrm{d}}$ University of Zurich (Switzerland)
}

\begin{abstract}
University technology transfer has attracted considerable attention in the literature with a focus on the institutions, the agents involved in technology commercialisation or the differentiation between formal and informal technology transfer mechanisms. There has, however, been little systematic research on how the mobility of university scientists influences their propensity to engage in technology transfer activities and, particularly, on how mobility influences the locus of such activities. This paper therefore analyses the link between university scientists' technology transfer activities and their international mobility patterns. We characterise scientist mobility along the two dimensions 'frequency' and 'intensity' resulting in an individual mobility pattern. We argue that the mobility pattern as well as the scientist's personal characteristics affects the likelihood whether a transfer of technology occurs to a firm in the scientist's home and/or host country. Based on a sample of more than 500 German university scientists, our results indicate that a substantial share of scientists engages in technology transfer both to the home as well as to the host country. There are, however, considerable differences regarding the factors influencing the locus of technology transfer.
\end{abstract}

Keywords: scientist mobility, university technology transfer, internationalisation

JEL classification: J61, O33

Acknowledgements:

The work has been carried out within a study for the German Federal Ministry of Research and Education (Edler, 2007). Financial support is gratefully acknowledged. Moreover, we thank Christian Rammer and participants at the international workshop on the labour market for scientists and engineers at Maastricht University, May 2008, for helpful comments and discussions.

1 Corresponding author, ZEW - Centre for European Economic Research, P.O. Box 1034 43, D-68034 Mannheim (Germany), e-mail: grimpe@zew.de, phone: +49-621-1235-381, fax: +49-621-1235-170 


\section{$1 \quad$ Introduction}

University technology transfer ${ }^{2}$ has attracted considerable attention in the literature with a focus on the institutions (e.g. technology transfer offices), the agents involved in technology commercialisation or on the differentiation between formal and informal technology transfer mechanisms (Bozeman, 2000; Link et al., 2006; Siegel and Phan, 2005). Particularly the individual scientist has been shown to play a key role in technology transfer activities (e.g., Siegel, 2004; Zucker et al., 2002). There has, however, been little systematic research on how the mobility of university scientists influences their propensity to engage in technology transfer activities and, particularly, on how mobility influences the locus of such activities. In order to broaden their knowledge and network, as well as to increase research productivity, many scientists visit other institutions located outside their home country. In fact, research stays abroad have gained considerable importance to build up reputation, to acquire collaboration partners and to increase chances for publication in international scholarly journals (Edler, 2007). The question how the scale and locus of technology transfer is influenced by the scientist's international mobility is important as it influences the way mobility affects innovation systems, both in the host and the home country of a mobile scientist. The effects of brain drain, gain or circulation have been subject to an intensive debate, both in the literature and in policy making, with attempts to leave the focus on negative home country effects (e.g. OECD, 2002b, 2007; Regets, 2007). In this respect, policy makers in all countries - not only in developing or emerging economies - remain worried about the potentially negative effects of outward mobility of scientists as knowledge and transfer potential might be 'lost' to the host country. When it comes to technology transfer from university scientists to firms, obviously, policy makers have an interest that international research activities result in a technology transfer to firms in the home and not only to the host country or even a third country.

Scientist mobility can occur in a variety of different forms. The literature has basically distinguished between mobility within the university sector and between university and industry. Intra-sectoral mobility refers to academics who either temporarily or permanently migrate to another research institution which might be located outside their home country (e.g., Mountford, 1997; for an overview see Nguyen, 2006). The discussion of this type of international scientist mobility is almost immediately connected with the public debate on brain drain affecting the technological capabilities and eventually the competitiveness of a country (Adams, 1968). Inter-sectoral mobility has become a buzz-word in many innovation policy strategies and recently been increasingly subject to analysis (Beckert et al., 2008), for example whether such inter-sectoral mobility induces a costly brain drain for public science (Toole and Czarnitzki, 2007). It seems that mobility of scientists, although highly praised as important for knowledge transfer and build-up of networks, cooperation potential and the like,

2 We will use the term 'technology transfer' as shorthand for a transfer of technological knowledge developed at a university or public research institute to a firm. 
does not loose its negative connotation of some kind of loss for the sending 'system', institution or nation.

This negative connotation is certainly true as regards outward mobility of scientists. Our focus will therefore be on intra-sectoral but international mobility of scientists at universities and government-funded research institutes and how this influences the nature and locus of technology transfer activities of these scientists. ${ }^{3}$ Thus, in the remainder of this paper 'mobility' refers to international mobility in the university sector. Given the variety of different types of mobility, we define scientist mobility as research stays that take longer than one month. Shorter activities, which would for example also comprise the attendance of international conferences, can be assumed to exhibit different characteristics than being embedded as a visiting scientist at a host institution. Scientist mobility can generally be characterised along two dimensions: the frequency as well as the duration of research stays outside of the scientist's home country. It can be assumed that the longer the duration of the stay the more intensive the experiences, the larger the networking potential and the more opportunities arise for the development, absorption or application of new technological knowledge. Consequently, longer research stays should result in higher embeddedness of the scientist in the host country Shorter but more frequent stays will presumably lead to a higher number of contacts and therefore also diversity or breadth of interactions, though less intensive interactions. Hence, frequency and intensity characterise the individual scientist's mobility pattern. The question we explore is how frequency and intensity influence the likelihood to engage in technology transfer activities, in the host and in the home country.

Although the mobility pattern is rather independent from a single research stay abroad we will assume in the following that distinct mobility patterns, along with the personal characteristics of the scientist like age, gender, scientific discipline or research productivity, determine the decision to transfer technological knowledge to the scientist's home country or to the host country. Thus we start off by endorsing the worries of policy makers when arguing that international mobility of scientists might benefit other countries more than the home country. As previous research on how international mobility of university scientists influences technology transfer and its direction is scarce, the character of our paper will be mainly exploratory. Our first objective is to provide information on the mobility behaviour of university scientists by identifying subgroups with a characteristic mobility pattern. Secondly, we aim at contributing empirical evidence on the determinants of technology transfer directed at the home or the (former) host countries of scientists. Hence, the remainder of the paper is organised as follows: The next section gives a brief review of scientist mobility and technology transfer and provides a synthesis of both in order to specify our research questions. Section 3 will provide an overview of our empirical methods before the subsequent section will show the results. We conclude by outlining the implications of our findings for science and technology policy and by indentifying further research opportunities at the intersection of technology transfer and scientist mobility.

3 In the following, we will use the term 'scientist' or 'scientist' as shorthand for scientists employed either at universities or government-funded research institutes. 


\section{$2 \quad$ A brief review of scientist mobility and technology transfer}

\subsection{Mobility of scientists}

A main perspective for the international mobility of scientists and highly skilled workers has been the so-called 'brain drain' discussion. At first glance, this goes back at least to Adams (1968) and has been coined in the context of development policy, analysing the scale, scope and consequences of the movement of scientific and economic elites from developing and emerging countries to a richer nation (Adams, 1968; Mountford, 1997; for an overview see Nguyen, 2006). However, while the discourse has long been focused on developing countries, initially the brain drain discussion was led in the United Kingdom in the 1950s and 1960s when recognising a loss of highly skilled workers and scientists to the United States (Cervantes and Guellec, 2002).

In the 1990s, the issue of economic consequences of scientist and highly skilled worker mobility came back on the agenda within the OECD (Salt, 1997; OECD, 2002a). As the capacity to conduct meaningful research has become a scarce resource, and as the importance of a sufficient pool of scientists and highly skilled workers has become more and more obvious, even developed countries have re-discovered worries about brain drain and looked for policy schemes to retain the scientific elites. Indeed, most of the literature and the public debate also within OECD and the European Union have - at first - discussed for many years the phenomenon of scientist mobility in a discourse of risk, of loss and of danger for the economy of the sending country. ${ }^{4}$ For example, the United Kingdom and the United States have intensified their efforts to re-attract or retain scientific elites at the end of the 1990s and beginning of 2000s (Cervantes and Guellec, 2002).

Studies have shown that mobility of scientists within the OECD countries has increased (Casey et al., 2001; OECD, 2002a). However, despite the risk discourse around it, this mobility is to a large extent of temporary nature, as $\mathrm{PhD}$ students and Post-Docs gain experience in other developed countries to come back and exploit this in their home country. Especially European governments have been worried about a potential brain drain to the United States but existing data show that the phenomenon in terms of long-term mobility, i.e. the emigration of scientists, is rather limited (Robinson et al., 2007; Cervantes and Guellec, 2002) Thus, the term brain circulation was coined in order to signal the potential gain of temporary mobility, as circulating brains would mean to link national science and innovation systems. European countries have intensified efforts to govern brain circulation (e.g., through the Research Framework Programmes of the European Union) in order to increase the benefit for European countries (e.g., Thorn and Holm-Nielsen, 2006).

\footnotetext{
4 For the developing countries - which are not within the realm of our paper - this is obvious, although some revisionist view in the 1990s has claimed the benefit for the sending country might be stronger than the costs, which is - at least - a highly contested conclusion (Fiani, 2003).
} 
A major rationale behind those circulation programmes has been that gaining knowledge abroad and becoming part of global networks enhanced the effectiveness of scientists and thus her or his contribution to science and - depending on the area - knowledge and technology transfer activities in the home country. In this regard, several studies looks at the barriers for mobility of scientists (e.g., Cox, 2008; Edler, 2007; Thorn and Holm-Nielsen, 2006), apparently assuming, at least on the side of policy makers, that more mobility in terms of brain circulation would lead to higher macro-economic benefit. This is an assumption that has led to a 'mobility strategy for the European Research Area (ERA)' whereby mobility - with a focus on circulation - is seen as a major pillar for the creation of a single European market in science and for the Lisbon Strategy in the area of science and technology (for a summary see COM, 2005).

A common belief in the debate on scientist mobility is that mobility enriches careers, creates networks, and helps to transfer knowledge and skills across borders, supports a better international flow of knowledge, better job matches through global job search and greater ability of employers to find rare or unique skill sets (Regets, 2007). All this allegedly leads to some form of cognitive integration in scientific fields across borders, facilitating complementarities in knowledge production. Regets (2007), in compiling international data with a focus on the US, claims not only an overall benefit for the global economy, but also benefits that exceed costs both for the receiving and the sending country when it comes to mobility of scientists. For the host country he claims increased incentive for natives to seek higher skills and thus an increase in domestic economic return to human capital investments, increased knowledge flows and collaboration as well as increased ties to foreign research institutions, export opportunities for technology and remittances and other support from 'diaspora networks'. Interestingly, he sees very similar effects for the receiving countries, thus making a strong argument for circulation and bi-directional benefits.

In sum, apparently the fear of brain drain in some OECD countries has made way for the hope for brain circulation and the realisation of related positive economic benefits. One increasingly recognised factor is the potential benefit for home countries of temporarily mobile scientists through an increased 'knowledge flow across borders' (Regets, 2007). This seems obvious. However, even these brighter interpretations of the consequences of mobility lack a severe shortage of empirical knowledge about the scope and scale of effects of brain circulation of public scientists for the economy of both receiving and sending countries. There are no analyses backed by clear empirical data regarding knowledge flows from public research to industry as a consequence of mobility. ${ }^{5}$ This is where this paper wants to contribute, in all modesty, some first findings.

The very general claims in some strands of the literature, whereby the build up of social transnational spaces inevitably also leads to an increase in transnational economic activity is interesting in itself (Pries, 2001), does however not help much when it comes to the question of our paper, i.e. how scientist mobility directly contributes to knowledge transfer to industry. 


\subsection{Technology transfer between academia and industry}

Today there is a wide agreement that technology transfer between academia and industry plays a crucial role for the economic development of firms as well as for the overall economic development. We use the term technology transfer in a broad understanding. First, it encompasses not only technological artefacts, but rather technological knowledge in general. Second, we do not only define technology transfer as transferring the results of university research activities to firms (in the understanding of the linear model, through licensing etc.), but also the transfer of technological knowledge that is demanded by firms in the form of contract research to find solutions for specific industrial problems and - beyond that - the coproduction of technological knowledge in the form of collaborative projects. This involves, therefore, the full scope of the 'mode 2' (Gibbons et al., 1994) and 'open innovation' (Chesbrough, 2003) understanding of sharing and co-producing knowledge. This already points to the need for proximity and the potential meaning of embeddness and persistence in international mobility.

Against this definition, the question remains on what the value of knowledge produced in universities can be for firms. To start with, firms need research results from public institutions, as they, in principle, refrain from investing in basic research (market failure argument). Firms are reluctant to invest in risky activity of which the results might be relevant for many actors beyond the firm itself. Furthermore, knowledge production involves high costs, as it is often too complex and dynamic for firms to cope with internally and on their own, relying on a vivid discussion of earlier research results (Dasgupta and David, 1994; Crespi et al., 2006). Firms thus need access to complementary research in public institutions, and - increasingly important - they need access to the scientists themselves, not least to acquire university personnel and thus to keep up their absorptive capacity for future transfer activities (Hall et. al., 2001).

Within the last couple of years there have been several studies evaluating these links between science and industry with a view to firm success. For example, Link and Scott (1998) revealed that the enactment of the Government Performance and Results Act (GPRA) of 1993, that has supported the link between academia and industry, has brought accountable benefits to the firms' economic development. Furthermore, Audretsch et al. (2002) have evaluated the effects of SBIR supported public-private technology partnerships. They found that public-private partnerships indeed create benefits for the participating firms.

A different strand of literature has examined the role of individual university scientists in the relationship between university and industry. For example, Zucker and Darby (1996) and Audretsch and Stephan (1996) have investigated the critical role of star scientists for the development of the biotechnology industry. They find that prestigious scientists promote the technological development of regional networks and the entrepreneurial activities in regions as well as the research productivity of firms, since they are more visible for entrepreneurs and established firms. In the more recent literature, the question has been analysed why scientists are interested in technology transfer. Hall et al. (2001) have outlined that the motives for scientists to participate in research joint ventures are mostly driven by financial considerations. Moreover, Owen-Smith and Powell (2001), Jensen et al. (2001) and Thursby 
and Kemp (2002) have highlighted the critical role of patents for technology transfer. They find that the awareness of commercialisation opportunities and an active involvement in the overlap between commercial and academic science of the faculty positively influence the patenting behaviour of scientists. Jensen and Thursby (2001) interviewed managers of technology transfer offices at US universities and observed that the disclosure of inventions in the eyes of the faculty is often problematic and requires the persuasion of the technology transfer managers. Thus the role of technology transfer offices as well as the standing of the technology transfer office manager plays a role for the engagement of scientists in technology transfer. This points to a basic trade-off in all university-industry relationships: academic reputation through publication of major new and influential findings vs. intellectual property for selected industrial actors and the financial income of universities and their transfer offices.

To sum up, the individual decision to engage in technology transfer is embedded in institutional contexts and the rationales, interests and framework conditions prevailing in them. Still, the decision of the individual scientist to transfer technological knowledge will depend also on the personal characteristics of the scientists (excellence, financial motivations, relevance of the research field, etc.). In the following, we will attempt a synthesis between the discussion of research mobility and technology transfer in order to outline the hypotheses guiding our research.

\subsection{Linking technology transfer with scientist mobility}

The previous sections have indicated that technology transfer from academia to industry is determined both by the personal characteristics of the scientist but also by the research environment. In the following we argue that it is also the scientist's mobility pattern which needs to be included into the analysis as one key explanatory variable. For this purpose we focus on the two dimensions of mobility: frequency and duration of research stays outside the scientist's home country. It can be assumed that the longer the duration of the stay the more intensive the experiences, the higher the embeddedness of the scientist in the host country, hence the larger the networking potential and the more opportunities arise for the codevelopment, absorption or application of new technological knowledge, be it codified or tacit. Hence, we label this dimension of mobility as intensity. In contrast, shorter but more frequent stays will presumably lead to a higher number of contacts and therefore also diversity or breadth of interactions - at the price of rather superficial contacts. Frequency and intensity therefore characterise the individual scientist's mobility pattern.

We assume the patterns of interaction abroad to have not only an impact on the transfer activities abroad, but also to have repercussions for transfer patterns at home. It is likely that there will be differences to the extent that frequency and intensity influence the propensity and effectiveness of technology transfer activities with firms in the home and host country. One assumption is that a technology transfer to firms in the scientist's home country is presumably easier to establish as there is, for example, no need to bridge cultural differences. Moreover, scientists will have fewer problems in their home country to signal the quality of their research to outsiders like firms that might be interested in research collaboration or commercialisation as they can benefit from an established reputation of their university which 
might, however, be unknown to firms in other countries. Thus, technology transfer to firms in the home country might benefit much more from a higher diversity of interactions with international colleagues which could be achieved through a higher frequency of research stays compared to a higher intensity. Contrary to this, the build-up of trust and the overcoming of frictions will take the scientist much more time in her or his host country than in the home country. Research stays will consequently have to be more intensive in order to leverage the networking potential and the opportunities for the development, absorption or application of new technological knowledge abroad. In other words, the scientist's embeddedness in the host country will presumably play a crucial role for a technology transfer to firms in the host country.

We thus can formulate two hypotheses. First, a mobility pattern characterised by high intensity will facilitate a technology transfer to the scientist's host country. Second, a mobility pattern characterised by high frequency will facilitate a technology transfer to the scientist's home country. Regarding the relationship between the individual scientist's characteristics and the decision to transfer technology to either the home or the host country we do not make any a priori hypotheses. This underlines the rather exploratory character of this study. The following section will outline our research methods that we used to test our hypotheses.

\section{$3 \quad$ Research methods}

\subsection{Data}

The data used in our empirical analysis stem from a survey among German scientists which was carried out on behalf of the German Federal Ministry of Education and Research (Edler, 2007). The aim of the survey, which was part of a large-scale project on the internationalization of German research and science, was to depict the willingness, the motives and the actual extent of international mobility of scientists in Germany. Data were collected in 2006 using an online survey instrument. On the one hand, contacting respondents via e-mail involves the risk of not reaching a considerable number of persons due to an outdated or misspelled e-mail address. On the other hand, e-mails have the advantage to be independent from space, i.e. the e-mail will reach the scientist although she or he might be away from the home office for a longer research stay outside of Germany. Two major data sources were used for the sampling procedure. In a first step, the population of scientists employed at German universities was derived from the 'Hochschullehrerverzeichnis' of the year 2005. The 'Hochschullehrerverzeichnis' is a database containing the names, degrees and contact information of the academic personnel employed at German universities. ${ }^{6}$ In a second step, scientists at government-funded public research institutes were identified via an internet search of the institutes' websites. These research institutes belong to the four large German science organisations: Max Planck Society, Fraunhofer Society, Leibniz Association and

6 This excludes the so-called 'universities of applied sciences' whose major task is teaching and not research. 
Helmholtz Association. In total, 113 German universities and 231 research institutes with around 20,000 and 10,000 scientists, respectively, were covered. ${ }^{7}$ Since the intention of the study had been to survey rather experienced scientists we limited the sampling to those scientists holding a $\mathrm{PhD}$. In order to stratify our sample we drew a random 50 percent sample from the university scientist group and hence ended up with around 20,000 scientists who were invited to participate in our survey.

The overall response rate was 15.8 percent which can be regarded as satisfactory for such a large-scale online survey. ${ }^{8}$ However, we limited the sample to those scientific disciplines where a transfer of technological knowledge can be assumed to occur, i.e. in agricultural and environmental sciences; biology and chemistry; physics, mathematics and information sciences; engineering sciences; medical sciences. In total, we retained the questionnaires of 1,509 respondents of which, however, 31 percent didn't report any international research experience longer than one month. Moreover, excluding cases with missing values leaves 516 observations available for analysis.

\subsection{Empirical proxy variables}

\section{Measuring technology transfer}

We rely on survey questions to qualify the technology transfer activities of scientists. The respondents were asked to indicate whether their most recent research activity outside of Germany resulted in a transfer of technological knowledge or expertise to a firm in Germany and/or in the host country.

\section{Capturing mobility patterns}

In our questionnaire, the respondents were asked to qualify their international mobility by indicating the number of stays abroad that lasted at least for one month and the respective duration. As has been noted before, it can be assumed that the longer the duration of the stay the more intensive the experiences, the larger the networking potential and the more opportunities arise for the development, absorption or application of new technological knowledge. We hence decided to construct two index variables that are used to condense the diverse mobility choices of the individual scientists. For the frequency index variable we summed up the number of all research activities outside of Germany that lasted at least one month and up to 12 months. For the intensity index variable we summed up all research activities abroad of more than 12 months. Obviously, a scientist's opportunities for international research activities are determined by age. We therefore include the career age,

There are of course also non German nationals employed at German universities and research institutes. In the questionnaire, those were asked whether they fill a permanent position. When their position was only temporary they received a separate set of questions which is, however, not further considered here.

8 This response rate does not account for the questionnaires that did not reach the scientists due to a wrong email address. The net response rate is therefore higher. 
defined as the number of years since the completion of the $\mathrm{PhD}$, to control for those age effects. Mobility patterns are then identified using a Latent Class cluster analysis. The results will be reported in section 4 .

\section{Control variables}

Our control variables centre on the characteristics of the individual scientist. We therefore chose a dummy variable indicating the gender and the career age in years. Scientific productivity is accounted for in terms of the number of publications in refereed journals in the past three years measured on an ordinal scale (none, 1-3, 4-6, >6) and whether the scientist had already applied for a patent. In contrast to German universities, the budget of government-funded research institutes typically exhibits a high share of third-party funds, e.g. from industry or foundations. Hence, we include a dummy indicating whether the scientist's home institution is such a research institute. Moreover, we include a dummy variable if the scientist received a grant for the research activity outside of Germany. Finally, we include the scientific discipline (agricultural and environmental sciences; biology and chemistry; physics, mathematics and information sciences; engineering sciences; medical sciences) as dummy variables.

\subsection{Estimation strategy and method}

Our empirical analysis has two major components which correspond to the two objectives of our paper. First, we would like to give an overview of the mobility behaviour of German university scientists. In other words, we suggest that subpopulations of scientists with distinctive mobility patterns exist in our dataset which will be of interest to discover. Secondly, we analyse the relationship between the mobility patterns, the scientists' personal characteristics and her or his inclination to transfer technology to firms in Germany or another country. While the former issue is typically addressed through cluster analytical methods, the latter requires a regression analysis. For the first step, we rely on a latent class cluster analysis. It was introduced by Lazarsfeld (1950) for identifying patterns in survey responses. Latent classes are unobservable (latent) subgroups or segments. The goal of latent class analysis is to identify subgroups of observations that are similar to other subgroup members, in terms of predefined variables, but dissimilar to members of other subgroups. In that sense, latent class analysis differs from other continuous latent variable approaches (like randomeffects regression) as the identification of groups (or categories) is the primary goal. It therefore follows a finite mixture model rationale of disentangling a dataset into a finite mixture from a finite number of distinctly different populations. It is superior to traditional cluster analysis as it is based on a statistical model which allows for significance tests and measurements of fit (Jensen et al., 2007; for a detailed discussion see Hagenaars and McCutcheon, 2002). Moreover, latent class analysis is able to cope with data measured on a nominal or ordinal measurement scale. The outcome of the analysis is an estimation of class membership given a scientist shows a characteristic mobility pattern. The mobility patterns will be discussed before they will be entered into the regression analysis further ahead. 
In the second step of our estimation we employ a seemingly unrelated bivariate probit model. The model reflects our choice of two dummy variables as dependent variables. Moreover, as outlined above, we are interested in the relationship between the two dependent variables. We have argued that a complementary relationship is reasonable to assume. In fact, the bivariate probit model also provides an indirect test for complementarity. The idea is to test for a positive correlation between the two practices conditional on a vector of covariates $X$ (Athey and Stern, 1998; Cassiman and Veugelers, 2006).

\section{$4 \quad$ Results}

\subsection{Identification of mobility patterns and descriptive statistics}

As outlined before, the first step of our analysis comprises the identification of clusters. Choosing the correct number of classes is an important step of the analysis because each additional class increases the fit of the model by capturing more heterogeneity. Then again, choosing too many classes makes it difficult to achieve meaningful interpretations for each class and the system as a whole. Hence, a parsimonious approach is required that balances both interests. This decision is typically based upon two key figures: the Bayesian information criterion BIC(LL) and the Akaike information criterion AIC3(LL). Both should be minimised to indicate an appropriate number of classes. In the following, we report all measurements of fit for a 1 to 5 class solution in Table 5 in the Appendix. The BIC criterion reaches its minimum for the 3-class solution while the AIC3 points to a 4-class solution. For interpretability reasons, we opt for the 3-class solution.

Table 1: Model for latent classes

\begin{tabular}{lrrrr}
\hline Parameters & $\begin{array}{r}\text { Class1 } \\
\text { 'intensive } \\
\text { travellers' }\end{array}$ & $\begin{array}{r}\text { Class2 } \\
\text { 'frequent } \\
\text { travellers' }\end{array}$ & $\begin{array}{r}\text { Class3 } \\
\text { 'home office } \\
\text { workers' }\end{array}$ & Wald (p-value) \\
\hline Frequency & -2.536 & 7.779 & -5.244 & 35.942 \\
Intensity & 15.583 & 16.542 & -32.125 & $\begin{array}{r}(0.000) \\
6.635 \\
\text { Career age }\end{array}$ \\
& -0.148 & 0.093 & 0.056 & 29.685 \\
Intercept & 0.576 & -0.230 & -0.346 & $10.000)$ \\
\hline Class size & & & & 19.169 \\
\hline
\end{tabular}

Table 1 shows the coefficients for the frequency, intensity and career age variables indicating an increasing or decreasing likelihood to belong to a certain class. We conduct Wald tests on coefficient significance. Significant differences between the classes can be detected for all variables. Scientists in class 1 are characterised by few but at the same time several long-term stays outside of Germany. Scientists in class 2 exhibit a high number of 
research stays but these had also a long duration. Class 3 shows negative coefficients for both frequency and intensity. Hence, less mobile scientists have a higher likelihood to be assigned to class $3 .^{9}$ To simplify the argumentation in subsequent parts of the analysis, we will refer to scientists in class 1 as the 'intensive travellers', in class 2 as 'frequent travellers' and class 3 as 'home office workers'. Class 1 is the largest, covering 56 percent of all observations. Class 2 follows with almost 33 percent while class 3 is the smallest with 11 percent.

International mobility of German university scientists can therefore be grouped within three distinct clusters. Apparently, there is rather large group of 'frequent travellers' who exhibit both frequent and at the same time longer research stays abroad. In other words, they show a high degree a internationalisation in their research activities. In terms of internationalisation, the 'frequent travellers' are followed by the 'intensive travellers' who prefer to stay abroad less often but rather long. Interestingly, more than half of all scientists in the sample belong to this group suggesting that this group exhibits the dominant mobility pattern. The lowest degree of internationalisation can be found among the 'home office workers'. But this group is also found to be the smallest with only 11 percent of all scientists. Obviously, international research stays have become rather a standard for university scientists. The three mobility patterns will be entered into the bivariate probit model to investigate their effect on the likelihood to transfer technology to a firm in Germany and/or in the scientist's host country. Before the multivariate analysis, Table 2 shows the descriptive statistics of the dependent as well as our control variables.

\section{Table 2: Descriptive statistics}

\begin{tabular}{lccccc}
\hline Variable & Obs. & Mean & Std. Dev. & Min. & Max. \\
\hline Transfer to Germany & 516 & 0.209 & 0.407 & 0 & 1 \\
Transfer to host country & 516 & 0.217 & 0.413 & 0 & 1 \\
Career age (years) & 516 & 16.581 & 10.380 & 1 & 41 \\
Gender (1=female) & 516 & 0.130 & 0.336 & 0 & 1 \\
Grant received (d) & 516 & 0.717 & 0.451 & 0 & 1 \\
Patent application (d) & 516 & 0.411 & 0.492 & 0 & 1 \\
Number of publications (ordinal) & 516 & 3.411 & 0.809 & 1 & 4 \\
Government-funded research institute (d) & 516 & 0.473 & 0.500 & 0 & 1 \\
Agricultural and environmental sciences (d) & 516 & 0.101 & 0.301 & 0 & 1 \\
Biology and chemistry (d) & 516 & 0.362 & 0.481 & 0 & 1 \\
Physics, mathematics, information sciences (d) & 516 & 0.310 & 0.463 & 0 & 1 \\
Engineering sciences (d) & 516 & 0.093 & 0.291 & 0 & 1 \\
Medical sciences (d) & 516 & 0.134 & 0.341 & 0 & 1 \\
\hline
\end{tabular}

The descriptive statistics show that about one out of five scientists has transferred technology to firms in Germany during a research stay abroad. Slightly more scientists have engaged in technology transfer to firms in their (former) host countries. Regarding our explanatory variables it turns out that scientists in our sample have on average been active after their PhD for 16 years. Thirteen percent of the scientists in the sample are female and more than 70 percent of the scientists received a grant for financing the international research

9 In the model for classes, the career age functions as a control variable as both frequency and intensity of research stays outside of Germany are affected by the scientist's age. The variable will therefore not be interpreted separately. 
activity. Around 40 percent have already applied for a patent and many scientists published more than six papers in refereed journals. Both variables hint at a rather high research productivity of the scientists in our sample. Receiving a grant is in fact another indicator for this high productivity as we assume that scientists who have received grants for their last research stay abroad have been in some way selected by the founding institutions for which one of the relevant factors is scientific excellence. Almost half of the scientists work at a public research institute. Regarding the scientific disciplines most of the scientists are in biology and chemistry as well as physics, mathematics and information sciences.

Table 3: Target regions of scientists

\begin{tabular}{lcc}
\hline Target region & Frequency & Percent \\
\hline Western Europe & 134 & 25.97 \\
Eastern Europe & 16 & 3.10 \\
North America & 305 & 59.11 \\
South / Middle America & 16 & 3.10 \\
Asia & 28 & 5.43 \\
Africa & 5 & 0.97 \\
Australia / Oceania & 10 & 1.94 \\
n/a & 2 & 0.39 \\
Total & 516 & 100.00 \\
\hline
\end{tabular}

Table 3 shows the target regions of the scientists' most recent research activity outside of Germany. Almost 60 percent of the scientists in our sample chose North America as their destination and about a quarter of them stayed in Western Europe. Surprisingly few German scientists chose emerging Asian countries like China or India for their research stay. Though we did not include the regions in the following regression, the information that 85 percent of the German scientists chose Western Europe or North America for their last research stay is valuable for the further interpretation of the regression results.

\subsection{Bivariate probit model}

Table 4 shows the results of the bivariate probit model. The second cluster ('frequent travellers') as well as the discipline 'physics, mathematics, information sciences' serve as reference categories in our analysis. 


\begin{tabular}{|c|c|c|c|c|}
\hline \multirow[b]{3}{*}{ Explanatory variables } & \multicolumn{4}{|c|}{ Technology transfer to firms } \\
\hline & \multicolumn{2}{|c|}{ in Germany } & \multicolumn{2}{|c|}{ in the host country } \\
\hline & coeff. & std. err. & coeff. & std. err. \\
\hline Cluster 'intensive travellers' (d) & -0.142 & $(0.238)$ & 0.392 & $(0.213)^{*}$ \\
\hline Cluster 'home office workers' (d) & -0.475 & $(0.237)^{* *}$ & 0.181 & $(0.224)$ \\
\hline Career age (years) & 0.005 & $(0.011)$ & 0.017 & $(0.009)^{*}$ \\
\hline Gender (1=female) & -0.186 & $(0.225)$ & -0.148 & $(0.213)$ \\
\hline Grant received (d) & -0.010 & $(0.145)$ & -0.118 & $(0.139)$ \\
\hline Patent application (d) & 0.679 & $(0.137)^{* * *}$ & 0.445 & $(0.133)^{* * *}$ \\
\hline Number of publications (ordinal) & -0.186 & $(0.083)^{* *}$ & -0.091 & $(0.078)$ \\
\hline Government-funded research institute (d) & 0.001 & $(0.135)$ & 0.245 & $(0.131)^{*}$ \\
\hline Agricultural and environmental sciences (d) & -0.051 & $(0.233)$ & 0.095 & $(0.233)$ \\
\hline Biology and chemistry (d) & -0.335 & $(0.175)^{*}$ & -0.105 & $(0.161)$ \\
\hline Engineering sciences (d) & 0.589 & $(0.223)^{* * *}$ & 0.308 & $(0.225)$ \\
\hline Medical sciences (d) & 0.285 & $(0.208)$ & 0.106 & $(0.215)$ \\
\hline Constant & -0.435 & $(0.448)$ & -1.259 & $(0.387)^{* * *}$ \\
\hline rho & \multicolumn{4}{|c|}{$0.760(0.048)$} \\
\hline Wald test of rho $=0$ & \multicolumn{4}{|c|}{$\operatorname{chi} 2(1)=76.866 ;$ Prob $>$ chi2 $=0.000$} \\
\hline Observations & \multicolumn{4}{|c|}{516} \\
\hline Wald chi2 (24) & \multicolumn{4}{|c|}{74.90} \\
\hline Prob $>$ chi2 & \multicolumn{4}{|c|}{0.000} \\
\hline Log (pseudo)likelihood & \multicolumn{4}{|c|}{-435.217} \\
\hline $\begin{array}{l}\text { Standard errors in parentheses. } \\
*, * *, * * * \text { indicate statistical significance at }\end{array}$ & 50 & $1 \%$ level & & \\
\hline
\end{tabular}

Focusing on the intensive travellers, the probit results show that those scientists have a higher propensity to transfer technology to firms in their host country but not to German firms. Our first hypothesis that a mobility pattern is characterised by high intensity will facilitate a technology transfer to the scientist's host country therefore receives support. The results for the frequent travellers have to be interpreted relative to the intensive travellers and the home office workers. As expected, scientists who travel rarely ('home office workers') have a significantly negative probability to transfer knowledge to Germany. Hence, frequent travellers can be assumed to be likely to transfer technology to Germany which provides support for our second hypothesis.

From the two included demographic variables, the career age has a significantly positive influence on the probability of German scientists to engage in technology transfer to firms abroad. An explanation for this positive relationship could be the fact that more experienced scientists have established networks with international partners over the years and thus engage more often in technology transfer to firms abroad than their younger colleagues. We cannot find any gender specific differences in the probability to engage in technology transfer nor does the grant seem to have any effect.

Scientists who have applied for a patent have a higher probability to transfer technology to firms in Germany as well as in their host countries. The decisive connection between patent applications and technology transfer as pointed out by Owen-Smith and Powell (2001) and Schmoch et al. (2000) can thus be confirmed. Furthermore, the results show that publishing papers in scientific journals impedes the propensity to transfer technology. This finding substantiates the trade-off between gaining reputation through publications and 
commercialising technology to firms. Scientists who are employed at a public research institute have a higher probability to engage in technology transfer to firms in their host countries due to their international activities compared to their colleagues at a university. Thus the findings of Dietz and Bozeman (2005), who have observed that university scientists in the United States increasingly engage in technology transfer compared to their colleagues at non-universitary research institutes can not be verified for German scientists.

The dummy variables for the scientific discipline of the scientists reveal that scientists from biology and chemistry compared to physics, mathematics, information sciences have a significantly negative probability to engage in technology transfer to firms in Germany, while these disciplines make no difference abroad. This might indicate a weakness of the German innovation system in the pharmaceutical and biotechnological domain in terms of the number of companies that are willing and able to absorb knowledge and provide sound conditions for cooperation with public scientists, while in other countries, notably the US, these conditions appear to be more favourable. In contrast to these findings, scientists from the engineering sciences have a significantly positive probability to engage in technology transfer to Germany. This finding may be attributed to the well established contacts between engineering scientists and industry in Germany.

Another important finding is the relationship between technology transfer to firms in Germany and, at the same time, to the host country, i.e. between our two dependent variables. It turns out that the rho correlation coefficient - conditional on the vector of covariates $X$ - is highly significant with a value of 0.76 . Apparently, there seems to be not a trade-off between both transfer directions but rather a mutually reinforcing, i.e. complementary, relationship. Even if this relationship is moderated by the different mobility patterns of the scientists, it shows that foreign technology transfer is not a substitute for activities at home, but a complement.

\section{$5 \quad$ Conclusion}

In this paper we investigate the variables that influence the likelihood of scientists to engage in - a broadly defined - technology transfer activities and we focus on the explanatory role of international mobility. Our results shed new light on the ways in which internationally mobile scientists engage in transfer activities both at home and abroad, and how the fact of being mobile affects the likelihood to transfer. For the first time, a large data set of scientists has been analysed along two dimensions: the frequency and intensity of scientist mobility. By way of a latent class analysis, these dimensions have been condensed to characteristic mobility patterns which were assumed to affect the technology transfer decision. For the conclusions, we thus can concentrate on those findings that are directly linked to international mobility rather than confirming, en passant, findings from earlier studies more generally (such as the finding that high publication activity correlates negatively with transfer activities). The questions we asked centre on how mobility impinges upon technology transfer and how 
different forms of mobility can influence the inclination to engage in transfer activities, and finally, what policy makers can learn from our results.

First of all, scientists who transfer knowledge do so, generally speaking, both at home and abroad. In other words, there is a complementary relationship between both activities. This is important as by each transfer activity knowledge accumulates and the subsequent transfer carries the knowledge of earlier transfers. Transferring knowledge abroad while being mobile thus will not diminish the activities and effects of subsequent transfers but rather increase them.

Second, we can confirm our first hypothesis, whereby the intensity of mobility has a positive impact on the inclination to transfer knowledge in the host country: while the simple transfer of artefacts or licenses can be done with short contacts, interactive transfer activities need intensity.

Third, and potentially more important, our results tend to confirm the second hypothesis, which stated that the more frequent scientists are internationally mobile, the more they engage in technology transfer to their home country. Those mobile German scientists who have been labelled as frequent travellers transfer more technology to firms in Germany than those who are not as often mobile, with immobile scientists being least active in transfer. Hence, for a country, it apparently pays off if the scientists are frequently mobile to other countries. At the same time, those scientists who are only intensively mobile, i.e. who stay abroad for a longer period but less frequently, transfer less to firms in Germany. Intensive mobility and embedding abroad might mean less embedding at home.

These results have basically two implications: (1) frequent mobility pays off for the innovation system of the scientist's home country, not only for the scientist personally, and (2) being not mobile is detrimental to technology transfer also at home. Form the perspective of the home country, i.e. the 'sending' country, support mechanisms pay off that enable scientists to get experience abroad, to broaden networks, to tie knots often. That would call for enabling frequent stays with a guarantee of returning, e.g. through secondments whereby scientists stay linked to their home organisation. Apparently, at least in the German context, supporting scientists at government-funded research institutes who tend to be less mobile than university scientists (Edler, 2007) is most effective in this respect. In Germany, there had long been a discussion as to how sensible it is to support mobility of such non-university scientists that are often more application and industry oriented. The answer is that it pays off for the whole system if the support is for frequent mobility rather than intensive mobility.

Consequently, in order to benefit from an inward mobile scientist, it is most beneficial for the host country if the scientist stays for a considerable time frame. Embedding into the host country system takes time and technology transfer within a foreign innovation system does, on average, not take place on a short term basis but needs the build-up of trust, networks and mutual recognition. From the perspective of host countries of foreign scientists this has important implications: to bring in foreign scientists should be linked to specific collaborative projects, as this increases the likelihood that firms in the host country do benefit from the 
transfer of knowledge. As a rule, brain gain in public science must be turned into a brain embedding through direct and close cooperation if the local industry is intended to benefit.

Our findings provide indications for policy makers on how to encourage technology transfer to the local economy following international research activities of scientists. Beyond that, they indicate that international mobility is part of an opening process of university scientists that benefits the home economy in many potential ways and thus needs not to be feared, but can be influenced for the better of the scientist, his or her scientific environment and his or her home economy.

Our study has shown how international mobility and technology transfer are linked. However, the data set cannot claim to cover all aspects of technology transfer, we have clearly concentrated on specific forms of cooperation. In doing so, we have neglected one link of technology transfer and international mobility - that we have not explored with our data which is yet to be analysed, i.e. the link between international mobility and inter-sectoral mobility. The latter refers to mobility from public to industry-funded research and has been shown to be an effective mechanism to transfer both codified and tacit knowledge (OECD, 2002a). It is obvious that those two activities could be and should be better linked, e.g. by analysing the scale and scope of cross-border mobility form the public research system into firms. If we want to understand the contribution of public research to globalisation of knowledge transfer, this gap needs to be closed soon. 


\section{References}

Adams, W. (1968), Introduction, in: Adams, W. (ed.) The Brain Drain, New York.

Athey, S. and S. Stern (1998), An Empirical Framework for Testing Theories About Complementarity in Organizational Design, NBER Working Paper No. 6600, Boston.

Audretsch, D.B., A.N. Link and J.T. Scott (2002), Public/Private Technology Partnerships: Evaluating Sbir-Supported Research, Research Policy 31, 145-158.

Audretsch, D.B. and P.E. Stephan (1996), Company-Scientist Locationai Links: The Case of Biotechnoiogy, American Economic Review 86 (3), 641-652.

Beckert, B., S. Bührer and R. Lindner (2008), Intersektorale Mobilität Als Form Des Wissenstransfers Zwischen Forschung Und Anwendung Verläufe Und Motive Von "Seitenwechseln", Isi Schriftenreihe Innovationspotenziale, Karlsruhe.

Bozeman, B. (2000), Technology Transfer and Public Policy: A Review of Research and Theory, Research Policy 29, 627-655.

Casey, T., S. Mahroum, K. Ducatel and R. Barré (2001), The Mobility of Academic Researchers: Academic Careers and Recruitment in Ict and Biotechnology, European Commission: Joint Research Centre (DG JRC) EUR 19905EN.

Cassiman, B. and R. Veugelers (2006), In Search of Complementarity in the Innovation Strategy: Internal R\&D and External Knowledge Acquisition, Management Science 52 (1), 68-82.

Cervantes, M. and D. Guellec (2002), The Brain Drain: Old Myths, New Realities, http://www.oecdobserver.org/news/fullstory.php/aid/673/The_brain_drain:_Old_myth s,_new_realities.html.

Chesbrough, H.W. (2003), Open Innovation: The New Imperative for Creating and Profiting from Technology, Boston.

COM (2005), A Mobility Strategy for the European Research Area; Researchers in the Era: One Profession, Multiple Careers, Commission of the European Communities staff working document: Implementation Report 2004 SEC(2005) 474

Cox, D. (2008), Evidence on the Main Fators Inhibiting Mobility and Career Development of Researchers, Draft Report, Manchester.

Crespi, G.A., A. Geuna and B. Verspagen (2006), University Iprs and Knowledge Transfer. Is the Ipr Ownership Model More Efficient?, SEWPS (SPRU Electronic Working Paper Series) No. 154, Brighton.

Dasgupta, P. and P. David (1994), Towards a New Economics of Science, Research Policy 3, 487-521. 
Dietz, J.S. and B. Bozeman (2005), Academic Careers, Patents, and Productivity: Industry Experience as Scientific and Technical Human Capital, Research Policy 34, 349-367.

Edler, J. ed. (2007), Internationalisierung Der Deutschen Forschungs- Und Wissenschaftslandschaft (Internationalisation of German Research and Science), Karlsruhe.

Fiani, R. (2003), The Brain Drain: An Unmitigated Blessing, Centro Studii Luca d'Agliano Development Studies Working Paper 173.

Gibbons, M., C. Limoges, H. Nowotny, S. Schwartzman, P. Scott and M. Trow (1994), The New Production of Knowledge: The Dynamics of Science and Research in Contemporary Societies, London.

Hagenaars, J.A. and A.L. McCutcheon (2002), Applied Latent Class Analysis, Cambridge.

Hall, B.H., A.N. Link and J.T. Scott (2001), Universities as Research Partners, NBER Working Paper No. 7643, Boston.

Jensen, M.B., B. Johnson, E. Lorenz and B.A. Lundvall (2007), Forms of Knowledge and Modes of Innovation, Research Policy 36 (5), 680-693.

Jensen, R.A. and M.C. Thursby (2001), Proofs and Prototypes for Sale: The Licensing of University Inventions, American Economic Review 91, 240-259.

Lazarsfeld, P.F. (1950), The Logical and Mathematical Foundations of Latent Structure Analysis, in: Stouffer, S. A. (ed.) Measurement and Prediction, Volume Iv of the American Soldier: Studies in Social Psychology in World War Ii, Princeton, 362-412.

Link, A.N. and J.T. Scott (1998), Public Accountability: Evaluating Technology-Based Institutions, Norwell.

Link, A.N., D.S. Siegel and B. Bozeman (2006), An Empirical Analysis of the Propensity of Academics to Engage in Informal University Technology Transfer, Available at SSRN: http://ssrn.com/abstract=902207 No.

Mountford, A. (1997), Can a Brain Drain Be Good for Growth in the Source Economy?, Journal of Development Economics 53 (2), 287-303.

Nguyen, C.H. (2006), Brain Drain or Brain Gain? The Revitalization of a Slow Death, http://www.usca.edu/essays/vol162006/chi.pdf.

OECD (2002a), Benchmarking Industry-Science Relationships, Paris.

OECD (2002b), International Mobility of the Highly-Skilled, Policy Brief No., Paris.

OECD (2007), The Oecd Stan Indicators Database 
Owen-Smith, J. and W.W. Powell (2001), To Patent or Not: Faculty Decisions and Institutional Success at Technology Transfer, Journal of Technology Transfer 26, 99114.

Pries, L. (2001), New Transnational Spaces. International Migration and Transnational Companies in the Twenty-First Century, London.

Regets, M. (2007), Brain Circulation: The Complex National Effects of High-Skilled Migration, Presentation at the Oecd Committee for Scientific and Technology Policy (Cstp) and Steering and Funding of Research Institutions (Sfri) Workshop on the International Mobility of Researchers, Paris, March 28, 2007.

Robinson, S., A. Mentrup, F. Barjak and M. Thelwall (2007), Collection and Analysis of Existing Data on Researchers Careers (Rescar) and Implementation of New Data Collection Activities, Final Report. Eu Contract No. 150176-2005-Fisc-Be, Brussels.

Salt, J. (1997), International Movements of the Highly-Skilled, OECD NEIM Division Occasional Paper No. 3, Paris.

Schmoch, U., G. Licht and M. Reinhard eds. (2000), Wissens- Und Technologietransfer in Deutschland, Stuttgart.

Siegel, D.S. (2004), Toward a Model of the Effective Transfer of Scientific Knowledge from Academicians to Practitiones: Qualitative Evidence from the Commercialization of University Technologies, Journal of Engineering and Technology Management 21, 115-142.

Siegel, D.S. and P. Phan (2005), Analyzing the Effectiveness of University Technology Transfer: Implications for Entrepreneurship Education, in: Liebcap, G. (ed.) Advances in the Study of Entrepreneurship, Innovation, and Economic Growth, Amsterdam, 138.

Thorn, K. and L.B. Holm-Nielsen (2006), International Mobility of Researchers and Scientists: Policy Options for Turning a Drain into a Gain, UNU World Institute for Development Economics Research (UNU-WIDER), Research paper series 2006/83.

Thursby, J.G. and S. Kemp (2002), Growth and Productive Efficiency of University Intellectual Property Licensing, Research Policy 31, 109-124.

Toole, A.A. and D. Czarnitzki (2007), Life Scientist Mobility from Academe to Industry: Does Academic Entrepreneurship Induce a Costly "Brain Drain" On the Not-for-Profit Research Sector?, ZEW Discussion Paper No. 07-072, Mannheim.

Zucker, L.G. and M.R. Darby (1996), Star Scientists and Institutional Transformation: Patterns of Invention and Innovation in the Formation of the Biotechnology Industry.

Zucker, L.G., M.R. Darby and J.S. Armstrong (2002), Commercializing Knowledge: University Science, Knowledge Capture, and Firm Performance in Biotechnology, Management Science 48 (1), 138-153. 


\section{Appendix}

\section{Table 5: Model goodness of fit}

\begin{tabular}{llllllll}
\hline No. of classes & LL & BIC(LL) & AIC3(LL) & L $^{2}$ & df & p-value & Class. err. \\
\hline 1-Cluster & -9080.880 & 18642.693 & 18359.759 & 1515.001 & 1395.000 & 0.013 & 0.000 \\
2-Cluster & -9013.062 & 18536.205 & 18236.124 & 1379.366 & 1391.000 & 0.580 & 0.114 \\
3-Cluster & -8979.727 & 18498.683 & 18181.455 & 1312.697 & 1387.000 & 0.920 & 0.206 \\
4-Cluster & -8969.287 & 18506.950 & 18172.574 & 1291.816 & 1383.000 & 0.960 & 0.269 \\
5-Cluster & -8965.097 & 18527.717 & 18176.194 & 1283.436 & 1379.000 & 0.970 & 0.311 \\
\hline
\end{tabular}

